\title{
WAYS OF IMPROVEMENT OF TECHNOLOGICAL EQUIPMENT PERFORMANCE
}

\author{
Mikhail B. Smirnov, Galiya B. Abdilova* \\ Shakarim University, Semey, Kazakhstan
}

Keywords: equipment, production losses, lean production, meat products, production system, efficiency and effectiveness measurement

\begin{abstract}
Increasing of production performance of production systems and equipment in the meat-processing industry is integrally linked to maintenance activities. The article analyzes the influence of technological effectiveness, level of hygiene, reliability and simplicity of equipment design on the main parameters of meat products quality. Here it is shown that the strategy of Total Productive Maintenance (TRM) and Lean production is important tool for assessment of parameter of the Overall Equipment Effectiveness $(O E E)$, which is used to assess the main types of losses that reduce the equipment productivity. The link of influence between the structural and mechanical properties of food masses, the moisture content of the initial food raw material, the temperature and viscosity, the processing pressure, and the density for the optimal operating terms of the equipment are analyzed in this research. With the help of OEE concept, the time losses related to the features of the equipment functioning are determined. The types of losses are classified as follows: downtime and readjustment (availability or readiness for operation) of equipment, short-term shutdown of equipment and a decrease in processing speed (productivity or performance rate of the equipment), product rejects and product losses (quality losses) during startup of equipment. While analyzing of the operation of vacuum filler for sausages production, the values of parameters of equipment availability, it productivity and product quality are calculated. The availability index is 0.79 , the productivity index is 0.76 , and the product quality index is 0.95 . Taking into account the obtained data on equipment availability, productivity and product quality, it is determined that the overall equipment effectiveness (OEE) accounts for 57\%. The application of this method for studying the overall equipment effectiveness operation can be applied to any technological equipment used in the meat-processing industry and allows eliminating many problems that arise during the operation of technological equipment, improving its technical and economic parameters, and developing a system of measures for improvement of its maintenance and repair.
\end{abstract}

\section{Introduction}

Due to the intensive increase in food consumption and change in structure of consumed food towards the higher quality and more diverse range of food products, the development of food industry currently has dramatic importance. Its efficient functioning is of critical importance for ensuring the food and economic security of a country and for improvement of the living standards of the population1.

Despite the fact that the current state of the industries engaged in processing of agricultural products is characterized by relative stability and significant potential to grow, the further development of the country's economy requires increasing the efficiency of domestic production, increasing its volumes, taking into account the competitiveness of the produced food products, in order to meet the needs of industry in raw materials in full range and to provide the population with food. Based on the basic socio-economic requirements for the development of the food industry, in the future, along with an increase in food production, it is necessary to raise the technical and technological level of production, create new types of products,

\footnotetext{
${ }^{1}$ Ponomareva, N.I., Nikitenko. V.S. (2005). The current state of the food industry in Kazakhstan: Analytical review. Almaty: KazGNINTI. 2005. - 69. (In Russian)
}

and improve the consumer quality of food products. The solution of these main tasks is possible on the basis of the introduction of scientific and technologic achievements in the most important areas of scientific and technological progress regarding to production, storage and processing of food products.

Among many branches of food industry in the Republic of Kazakhstan, the production of meat and meat products is traditionally considered one of the main and prior spheres of agriculture. However, the technical condition of the most of meat processing enterprises requires a thorough renovation and reconstruction. Taking into account the features of an enterprise, its production goals and objectives, the market for production equipment to produce semi-finished meat products can offer domestic or imported technological lines, as well as some separate units of equipment.

Despite this, the management of each enterprise encounters questions related in some way to improvement of equipment effectiveness, its maintenance and its repair. To solve these issues during the operation of equipment it is necessary to apply approaches and methods which ensure its high productivity, produce high-quality product, and reduce idle time by reducing of unplanned downtime. 
In this case, the introduction of lean production methods makes it possible to form a more responsible arrangement of production processes, to find reserves for increasing the production rate due to more efficient use of existing technological capacities, and also to reduce the cost of production [1]. Currently, the term "lean production" is being implemented at enterprises in many countries and in various industries $[2,3]$.

Within the "lean production" system a range of methods can be offered, which use will increase production effectiveness, for instant the principle of "kaizen" (continuous improvement of production processes), "5S System" (due arrangement of the workspace and optimization of labor), "TPM" (Total Productive Maintenance - a system of total productive equipment maintenance), etc.

In particular the target of the TPM program is to eliminate losses related with equipment maintenance. The "TPM" is based on eight principles aimed at preventive methods of maintaining the reliability of equipment $[4,5]$ :

1 Autonomous maintenance (making operators responsible for routine maintenance);

2 Scheduled maintenance (development of procedure and schedule of maintenance);

3 High-quality service (finding and prevention of errors);

4 Continuous improvement (based on the concept of "kaizen");

5 Early management of the equipment (creation of a management system for development and introduction of new equipment);

6 Training of employees (improving the awareness of staff involved in the service);

7 Safety, health, environment (creation of a safe and healthy working environment in the workplace);

8 Administrative and office TPM (elimination of losses in the administrative functions).

Due to preventive repair and maintenance of equipment in operable condition, its maximally productive, economical use is achieved [6].

The obligatory condition for production of high-quality products is the perfect operable state of machinery (equipment, tooling), materials and methods (service system, methods of operation and measuring methods). The efficiency of the major production becomes increasingly dependent on the services and servicemen assigned to ensure the maintaining the working equipment and tools in operable condition with minimal costs of repair. For the main production, it is necessary to supply raw materials, other materials, semi-finished products, power of various types, tools, transport [7].

The implementation of all these diverse functions is the task of various auxiliary divisions of an enterprise - department of repair, tools, power supply, transport, warehouse, etc. Improving the efficiency of technical maintenance of production in whole to the greatest extent depends on correct organization of those departments and further improvement of their work.
Like any other process the TPM function must be continuously improved to minimize maintenance and repair costs and maximize equipment availability and performance. While that an important tool for the strategy of Total Productive Maintenance (TPM) and of Lean production is the parameter of the overall equipment effectiveness (OEE), which is used to estimate the main types of losses which cause reduction of equipment operation effectiveness $[6,7,8,9]$. KPIs are three metrics as follows, namely: equipment availability, productivity, quality. The first two parameters (availability and productivity) take into account the loss of time from equipment downtime, and the quality metric takes into account the loss of quality during production of the finished goods.

Improving the equipment availability and productivity usually requires reengineering, which does not always require replacement of existing equipment with the new ones. The desired result can be achieved due to the high availability of equipment, caused by reliability and maintainability of the equipment. Therefore, the maintenance function is vital for sustainability of any manufacturing facility, and according to Pareto rule of 80-20, which implies that most part of efforts is inefficient and must be reduced, it follows that $80 \%$ of maintenance costs and repair costs are spent on maintenance of $20 \%$ of equipment $[10,11]$. This very problematic equipment must be revealed and special attention must be focused on it.

\section{Materials and methods}

Depending on the processing and cooking methods, the composition of raw materials of the minced meat is quite diverse. It is explained by the varying degree of mechanical processing, moisture level, fat content and other factors. Therefore, the production compositions of minced meat used in sausages production were selected as the objects of research.

The important element in determining the efficiency of equipment operation is the arrangement and monitoring of work to collect information on losses that cause the greatest problems in the process of operation of technological equipment. It is recommended to use Pareto analysis to process the obtained data. Pareto chart is a way of graphing data that allows identifying a few, but important factors that make the greatest impact on losses, in order to focus the primary efforts on eliminating or reducing the influence of these factors. Continuous monitoring of the overall efficiency of the equipment will reveal not only downtime due to breakdowns, but also losses due to ineffective adjustment or tuning of equipment, decrease in its performance or idle time due to waiting for the materials $[12,13]$.

\section{Results and discussion}

Technological processes in the food industry are numerous and various, however they have in common that the original organic raw materials are processed into finished food products. This circumstance determines the 
specific feature of food production, and that is the absolute cleanliness for acceptance of raw materials, storage and processing of food products, and protection of food products from pollution and spoilage, as well as from accidental admixture of foreign substances and objects.

Taking into account the specifics of food production, i. e. the manufacture of semi-finished or finished food products, it is necessary to comply with a number of requirements for food equipment [14]:

- technological effectiveness of equipment - implementation of established technological processes at each stage of processing of food raw materials (maximum use of the raw materials and preservation of its nutritional value);

- high level of hygiene of the equipment, which defines the quality of the produced food (high level of hygiene of working parts and their surfaces in contact with the product must be made of corrosion-resistant construction materials);

- equipment reliability - the maximum probable duration of operation (failures in operation lead to a decrease in rate of productivity, to disruption of the technological process and loss of product);

- simplicity of equipment design (ease of disassembly and assembly of the working mechanisms, availability of free access for repairs, sanitization and maintenance, simplicity of units, working and most wearing parts must be easily replaceable).

The design of the working parts of a machine must exclude unnecessary grinding of the processed raw materials, chance of getting the lubricating oils, rust or metal dust caused by wear of parts into the processed food mass.

Currently, food industry enterprises use high-performance equipment, create production lines for the manufacture of various semi-finished products and finished products; introduce new continuous technological processes into production based on cut-the-edge technologies. Meanwhile any measures, applied to ensure the growth of production, must provide for a more complete and efficient use of machinery and equipment, elimination of downtime, reduction of the time required to master the new equipment, and for further intensification of production. In addition, it is necessary to keep in mind that equipment is one of the factors which influence the quality of products. The properties of equipment can be determined through the structural and mechanical characteristics (SMC) of the used raw materials and the influence of various technological factors on SMC [15]. The necessity to comply with technological modes and conditions of production to reduce rejects and improve quality during production of cooked sausages was stated by L. S. Kudryashov in his research [16].

The influence of various technological factors on structural and mechanical properties of food masses.

The quality of finished food products depends on quality of the raw materials. The quality of raw materials is greatly influenced by processing and compliance with the technological recipe.

The wide variety of raw materials and products make it inevitable to use many fundamentally different technologies, types of machines and devices. Compliance with the optimal technological and mechanical parameters in the production of semi-finished food products at certain stages of their processing, using rheological methods, allows stabilization of yield and quality of the finished products. A set of functional, technological, structural and mechanical parameters is used to predict the behavior of raw meat during technological processing. The set of parameters objectively reflect its quality ( $\mathrm{pH}$ value, water-binding and fat-holding capacity, water activity, stickiness, viscosity, plasticity, etc.) [17].

The process of food media forming is one of the most complex processes in the food industry because of the specificity and variety of types of the processed raw materials. The entire range of physical and chemical properties of the formed material is observed in this process in all its wide diversity, as well as changes in structural and mechanical properties during processing and in dependence with various technological factors. Therefore, the design schemes of the forming machines are completely determined by the technological properties of the food media accordingly.

Accurate observance of the minced meat recipe in terms of the quantitative and qualitative composition of raw materials and additives, ensuring optimal conditions for its preparation and optimizing the processes of extrusion and forming the sausages guarantee the obtaining high-quality products. Meanwhile it is necessary to note that the processes of extrusion, dispensing and forming (molding) are not yet mechanized enough and still very manual labor consuming. When forming sausages, the structural and mechanical properties of minced meat and their changes during processing, the working pressure when stuffing (filling) the minced meat into a sausage casing or mold, temperature changes in the casing during heat treatment of sausage loaves are not taken into account. Many of these disadvantages occur in dosing and forming / molding machines used in both large and small meat processing plants. One of the important directions in optimization of stuffing process is the correct selection of the stuffer and determination of the range of its practical use [18].

In order to regulate the technological processes, determine the optimal operating modes of the sausage forming equipment, it is necessary to monitor constantly the quality properties of the processed product based on its structural and mechanical properties, which are most sensitive to changes in various technological and mechanical factors.

Duration of ripening. To determine the influence of various factors on the structural and mechanical properties of minced meat, it is important to know the duration of period during which its properties $\left(\Theta_{0}, \eta, B, m\right)$ after their forming remain practically constant. 
Studying the effect of ripening on shear properties, A. V. Gorbatov noted that in the first two hours of ripening of minced meat its properties practically do not change [19].

In case of sausages ripening for $4-10 \mathrm{~h}$ (second period), all parameters $\left(\Theta_{0}, \eta, B, m\right)$ increase to a maximum (critical ripening time). While that period the process of spontaneous hardening finishes, moisture completely saturates all existing bonds. This is important to know when preparing sausages for heat treatment.

Further exposure (third period) causes a decrease in values of all properties due to weakening of the sausage structure under the influence of microbiological and biochemical processes.

Moisture. Moisture is one of the main technological parameters for many food products. The water content and moisture content determine the quality of the food. They have a significant impact on the flavor, appearance, texture and shelf life of foods.

For sausage minced meat, along with an increase in humidity the liquid layers of dispersion medium between the particles gets thicker, the concentration of proteins in solution of interlayers decreases, their viscosity, structural strength and the values of structural and mechanical properties decrease also [20]. At the same time, this leads to an increase in the yield of products, reduces the load on all elements of processing machines.

The process of thickening of liquid layers is inhibited by the reverse process - swelling of muscle fibers, increase of their surface and binding of moisture, which contributes to increase in strength. The cumulative effect of these processes in general leads to minor decrease in strength of structure of minced meat.

Pressure. As a rule, the structural and mechanical properties of food products are determined at atmospheric pressure, which does not correspond to the conditions under which the product in processed and transported. In most cases the processes of forming / molding, pressing, transportation, etc. take place under conditions of allround compression; therefore, to obtain a finished product of high quality, it is necessary to take into account the effect of pressure on its structural and mechanical properties.

Density is an essential characteristic when calculating a number of machines and processes. Like in many liquid products, the density of viscous-plastic food products increases with increasing of pressure.

For a range of sausage mince production compositions (milk sausages, milk sausages, diet sausages, table sausages, diabetic sausages), the density, depending on pressure, changes according to the logarithmic law and can be determined from the following dependence

where

$$
p=a_{1}-\left(a_{2} \varphi+a_{3} U\right)+a_{4} \lg Y
$$

$a_{1}$ - is the coefficient, $\mathrm{kg} / \mathrm{m}^{3}$, numerically equal to

1052 at $0<p \cdot 10^{-5}, \mathrm{~Pa} \leq 2,5$,

1107 at $2,5<p \cdot 10^{-5}, \mathrm{~Pa} \leq 16$;
$Y=\left(p \cdot 10^{-5}+1\right)-$ modulus (numerical value) of absolute pressure;

$a_{2}, a_{3}-$ empirical coefficients, $\mathrm{kg} / \mathrm{m}^{3}$, respectively equal to 270 and 10,5;

$a_{4}-$ coefficient, $\mathrm{kg} / \mathrm{m}^{3}$, numerically equal to

143 at $0<p \cdot 10^{-5}, \Pi a \leq 2,5$,

47 at $2,5<p \cdot 10^{-5}, \Pi a \leq 16$;

$\varphi$ - fat content of minced meat $(\mathrm{kg}$. of fat per $1 \mathrm{~kg}$. of minced meat);

$U$ - moisture content of minced meat (kg. of moisture per $1 \mathrm{~kg}$. of dry residue).

The equation (1) is valid at pressure $(0 \div 16) \cdot 10^{5} \mathrm{~Pa}$.

It was found that the highest compaction of minced meat is observed within the pressure range $p=(0 \div 16) \cdot 10^{5} \mathrm{~Pa}$. At high pressures the density of minced meat increases only insignificantly. The obtained data allows determining the volume of the product in a compressed state and after discharge of pressure.

With increasing pressure, the values of the structural and mechanical characteristics of the minced meat also increase - the ultimate shear stress $\theta_{0} \mathrm{~Pa}$, effective viscosities at unit velocity $B \mathrm{~Pa} \cdot \mathrm{s}$ and unit gradient of velocity $B_{0}^{*} \mathrm{~Pa} \cdot \mathrm{s}$, rate of structure destruction $\mathrm{m}$. Plastic viscosity $\eta_{p l}$ Pa.s practically does not depend on pressure.

The change in main values at different pressures happens mainly due to the reorientation of particles and their denser compaction, with subsequent increase of interaction in contact surfaces of the coagulation structure of the minced meat, and to destroy this system more intense external influences are required.

Temperature and viscosity. Meat and meat products are complicated substances in their chemical composition and have a complex of various properties that together make up the quality of products. In this case the structural and mechanical properties stipulate the behavior of meat and meat products in a stressed state, which main parameters under applied force are stress, magnitude and rate of deformation. Awareness of these parameters as well as defining of their dependence on various factors have great practical importance for obtaining objective information about the state of the product at various stages of its processing. This information is also needed for development of new technologies and methods of control over technological processes, and for technological design of machines and devices [19].

In production of sausages, which occupy a leading place among other meat products, with the help of devices that allow measuring structural and mechanical properties, it is possible to control the technological parameters of raw materials and minced meat, quality of product at any stage of minced meat processing (from ripening of meat to stuffing of minced meat into sausage casing or mold), as well as the chewy texture of finished products [18].

During production in majority of cases technological processes occur in conditions of changing temperature. Therefore it is important to know the influence of tem- 
perature on structural and mechanical properties of the processed meat mass, which will make it possible to determine the optimal operating modes of the sausage forming equipment.

Structural and mechanical properties (ultimate shear stress $\left(\theta_{0}, \mathrm{~Pa}\right)$, effective viscosity $\left(\eta_{\text {ef }}, \mathrm{Pa} \cdot \mathrm{s}\right)$ and plastic viscosity $\left(\eta_{p p} P a \cdot s\right)$, effective viscosity at unit velocity $(V)$, effective viscosity at unit gradient of velocity $\left(B_{0}^{*}\right)$, the rate of the structure destruction $(m)$ was determined within the range of temperature from 275 till $313^{\circ} \mathrm{K}\left(2-40^{\circ} \mathrm{C}\right)$ for minced meat of industrial production composition - milk sausages, diet sausage, milk sausage, diabetic sausage, special sausage.

When processing the experimental data, it was found that an increase in temperature leads to decrease in values of investigated structural and mechanical properties. This is caused by the fact that an increase in temperature leads to a weakening of bonds in the introductory-protein-salt layers due to decrease in the solvent viscosity and a more intense thermal motion of molecules. This mechanism of the temperature effect on the product leads to a weakening of the strength of the structure as a whole.

To calculate the effective viscosity $\left(\eta_{\mathrm{ef}}\right)$ at different temperatures the generalized equation is suggested

where

$$
\eta_{e f_{t}}=A B_{0_{\text {red }}}^{*} \cdot e^{E / R T} \cdot\left(\dot{\gamma} / \dot{\gamma}_{1}\right)^{-m} \text {, }
$$

$A-$ is pre-exponential factor;

$B_{0_{r e d}}^{*}-$ is the reduced effective viscosity at a unit velocity gradient, $\mathrm{Pa} \cdot \mathrm{s}$;

$E$ - is the energy of activation, $\mathrm{kJ} / \mathrm{kmol}$;

$R-$ is the universal gas constant, $(8,32 \mathrm{~kJ} / \mathrm{kmol} \cdot \mathrm{K})$ );

$\mathrm{T}$ - is the absolute temperature, ${ }^{0} \mathrm{~K}$;

$\dot{\gamma} / \dot{\gamma}_{1}=\dot{\gamma}_{*}-$ is the numerical value of the velocity gradient;

$\dot{\gamma}_{1}$ - is the unit value of the velocity gradient;

$m$ - is the rate of destruction of structure;

$B_{0_{t}}^{*}=A B_{0_{n p}}^{*} \cdot e^{E / R T}-$ is the effective viscosity at the unit veloc-

ity gradient and at any temperature.

The coefficients $A$ and $E$ have the following values depending on the temperature:

Within the temperature range $(275-299,5){ }^{0} \mathrm{~K}-$ $A=0,055, E=7074$;

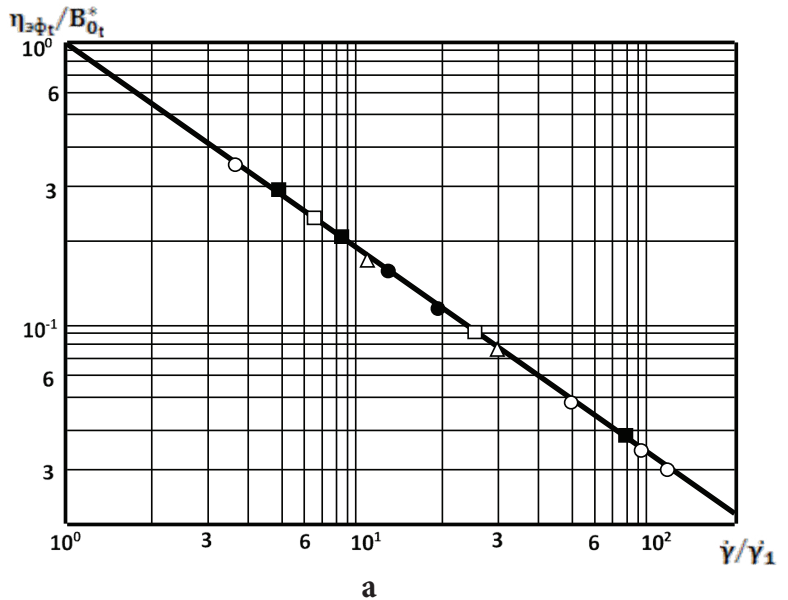

Within the temperature range $(305-313)^{0} \mathrm{~K}-A=0,022$, $E=6428$.

For practical application of results of this research a graphic analytic method for determination of the effective viscosity at any values of velocity and temperature gradient within the studied ranges is proposed (Figure 1) [21].

Each section of the straight line in the figure " $1 \mathrm{~b}$ " corresponds to its own value of the activation energy. Moreover, the change in the activation energy does not occur continuously, but occurs in the form of activated bounces, which is caused by melting of fat contained in sausage meat.

The first inflection point at a temperature of $299.5^{\circ} \mathrm{K}$ corresponds to the beginning of fats melting and, apparently, is the limit of a quantitative change of structure. In section 2-3 the crystallization structure begins to break down spontaneously with a simultaneous increase in fluidity, while most of the components turn into a liquid state. The melting point of $305.5^{\circ} \mathrm{K}$, corresponding to the second inflection point, can be considered as qualitative boundary of state change, which features the transition of minced meat from the crystallization structure to the coagulation structure.

The temperature of about $31{ }^{\circ} \mathrm{K}$ corresponds to the beginning of the manifestation of denaturation processes and the transition of minced meat from a plastic-viscous state to an elastic one. The effect of the onset of denaturation must be taken into account when considering a number of technological processes.

The value of the effective viscosity at different temperatures according to the graphs shown in Figure 1 is determined in two stages. According to the graph (Figure $1 \mathrm{~b}$ ) at a given temperature, in the specified range, we find the value of the effective viscosity at a unit gradient of velocity $\left(B_{0_{t}}^{*}\right)$. Then, according to the graph (Figure $1 \mathrm{a}$ ), we determine the effective viscosity $\left(\eta_{\text {eft }}\right)$ according to the value of the velocity gradient obtained as a result of viscometric studies.

Considering that even small changes in temperature cause significant changes in viscosity and other structural and mechanical properties, it is necessary to strictly comply with the temperature modes for production of minced meat and ready-to-eat food products, made of it.

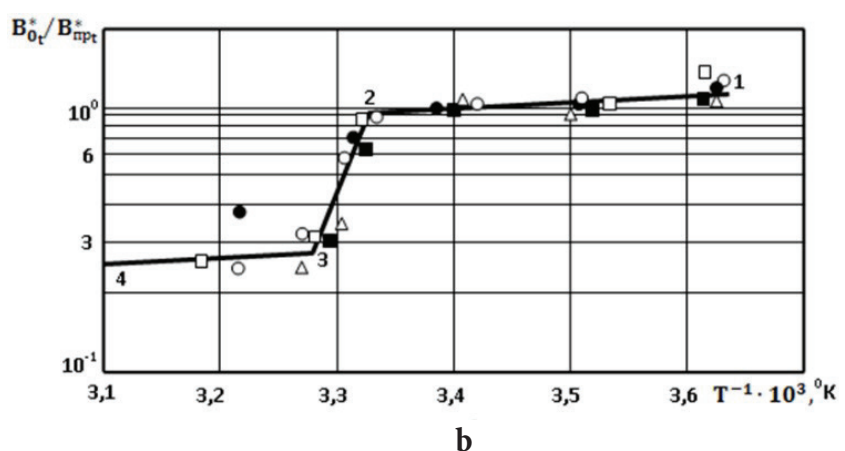

Figure 1. Dependence of the effective viscosity on the gradient of velocity (a) and on temperature (b) for minced meat: $\bigcirc$ - dairy sausages; $\square-$ special sausage; $\Delta$ - diabetic sausage; $\bullet-$ milk sausages; - diet sausages 


\section{The flow of food masses in circular channels}

When shaping sausages, one of the final stages before filling the sausage casing is the movement of the minced meat along the channel of the sausage stuffer, which is a circular channel of a certain length.

Currently a wide range of theoretical and empirical equations are known for calculation the process of food product movement along the circular channels, since they are used in a device for molding of food masses, as interoperative transport, and also in capillary viscometry [22]. The mathematical description of the product behavior is a prerequisite for the engineering design of the flow process.

Since the capillary diameter can reach several tens of millimeters for high-viscosity non-Newtonian fluids and plastic-viscous systems, it is important to define the distribution of velocities and deformations over the cross section of the mass flow during the movement of the food product.

The speed of the minced meat flowing out of the stuffer horn has a significant effect on both the state of the minced meat and the productivity of the stuffing machine. The larger is the diameter of the stuffer horn, the lower is the flow rate, the less pronounced changes in the structural and mechanical properties of the minced meat are observed and the higher is the productivity of the equipment [20].

In the majority cases all types of minced meat used for the production of sausage products can be attributed to viscous-plastic materials, and an increase in the shear rate creates not only a conventional shear stress, but also leads to normal stresses that lead to swelling of the meat flow in the moment of its exit from a stuffer horn or capillary (Barus effect). This phenomenon was established when studying the change in pressure along the length of the minced meat line at different flow rates of minced meat and is very important in assessing the applicability of minced meat for processing.

When flowing through short channels, it is possible to determine the pressure loss by estimating the difference between the pressure in the food mass reservoir at the inlet point to the stuffer horn and the ambient pressure at the outlet from the stuffer horn. The measured pressure difference is greatly influenced by the so-called input effects caused by non-laminar flow in the inlet area and unsteady flow conditions. To minimize the end effects (at the inlet and outlet of the channel) on pressure loss, they use capillaries with a high capillary length ratio (stuffer horn) $L$ to its diameter $D(L / D=20 / 1$ or higher) [23].

In theory of flow of any media, the basis for calculating of pipelines parameters is definition of the type of function. It allows calculating the velocity and the velocity gradient over the cross-section of the live flow.

The velocity profile is quite comprehensively characterized by the ratio $u_{\max } / w$. In theory this ratio varies from one to three, depending on the flow mode. The consideration of the "power-law fluid" motion model significantly expands the understanding of flow modes.
Theoretical velocity distribution profiles for round pipe, composed with different fluid flow index, according to the following equation

$$
u / w=(1+3 n) /(1+n)\left[1-(r / R)^{\frac{n+1}{n}}\right]
$$

and theoretical velocity gradients distribution profiles, composed accordingly upon the following equation

$$
\gamma^{\cdot}=\partial u / \partial r=-w / R((1+3 n) / n)\left((r / R)^{1 / n}\right)
$$

are in good agreement with the experimental distribution profiles of velocities and velocity gradients [24] and thus they indicate the presence of two zones - a wall layer, i. e. annular layer with a thickness of $\delta=R-R_{1}$, and the main flow with radius $R_{1}$ (Fig. 2).

In the equations 3 and 4 above the following notations are used: $u$ - velocity of elementary layer, located at a distance $r$ from the pipe axis, $\mathrm{m} / \mathrm{s} ; w-$ average velocity of flow, $\mathrm{m} / \mathrm{s} ; n$ - index of flow; $R$ - inner radius of a pipe, $\mathrm{m}$.

As can be seen from Figure 2 below, the sausage meat is exposed to the greatest deformations in the wall layer, where there is a sharp change in speed. The core of the flow moves in the form of a quasi-solid rod.

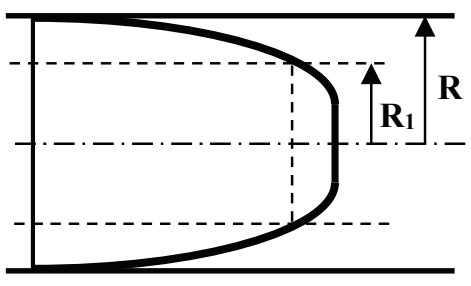

Figure 2. Diagram of flow of minced sausage meat in a round pipe

Analyzing the experimental and theoretical profiles of distributions of velocities and velocity gradients, it can be noted that for any flow index, the greatest change in velocity within 0.8 of the maximum velocity occurs within the wall layer. It allows determining the thickness of the wall layer when the sausage meat moves in a round pipe. Basing on this it is possible to write down the following

$$
\dot{\gamma}\left(R_{1}\right)=0,2 \dot{\gamma}_{\max }
$$

where $\dot{\gamma}\left(R_{1}\right)$ - in the gradient of velocity in the flow layer at the distance $R_{1}$ from the axis, $\mathrm{s}^{-1}$.

The maximal gradient of velocity has the following form

$$
\dot{\gamma}_{\max }=-w \cdot((3 n+1) / n) \cdot 1 / R
$$

And the gradient of velocity in the layer of flow at a distance $R_{1}$

$$
\dot{\gamma}\left(R_{1}\right)=-w \cdot((3 n+1) / n) \cdot 1 / R \cdot\left(R_{1} / R\right)^{1 / n},
$$

where $w$ - is the average velocity, $\mathrm{m} / \mathrm{s} ; n-$ index of flow.

So the equation 5 has the following form, taking into consideration the equations 6 and 7

$$
\left(R_{1} / R\right)^{1 / n}=0,2 \text { or } R_{1}=0,2^{n} R \text {. }
$$

At the known value of $R_{1}$ the thickness of the wall layer $\delta$ any index of flow can be determined by the dependence

$$
\delta=R-R_{1} \text { or } \delta=R\left(1-0,2^{n} R\right) .
$$


To determine the velocity gradient in the wall layer and the relative thickness of the gradient layer, the graphs of their dependence on the flow index are plotted below (Figure 3).

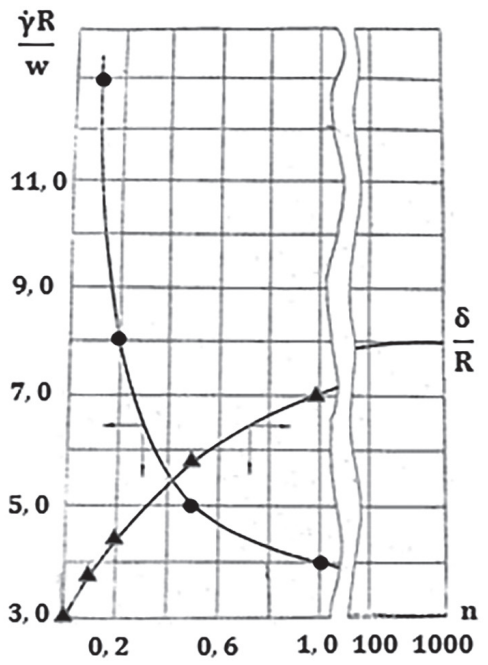

Figure 3. Dependences of maximal gradients of velocity and thickness of the gradient layer on flow index

\section{Determining the effectiveness of the equipment}

For the successful operation of any type of company, it is necessary to objectively assess the actual efficiency of using the available equipment. The availability of this information will eliminate a range of problems that arise during the operation of technological equipment, improve its technical and economic performance indices, and develop a system of measures to improve its maintenance and repair. As an assessment of the efficient operation of equipment, the concept of Overall Equipment Effectiveness (OEE) can be proposed, which allows to determine all losses of working time that affect the operation of the equipment (Figure 4) $[6,9,25]$.

In accordance with Fig. 4 , the overall equipment effectiveness (OEE), expressed as a percentage, is calculated by the following formula

where

$$
O E E=(B / A) \cdot(D / C) \cdot(F / E) \cdot 100,
$$

$B / A-$ availability of equipment (loss of time due to equipment downtime);

$D / C$ - productivity (loss in speed due to short-term shutdown of equipment and, as a result, a decrease in throughput capacity);

$F / E$ - quality of product (loss in quality due to the production of products below the quality standards).
Waste reduces overall production efficiency. In international practice, it is considered to be a bad OEE of less than $65 \%$, satisfactory - from $65 \%$ to $75 \%$, good - more than $75 \%$ [25].

When assessing the operation of equipment, six types of losses are usually defined, which can be classified as follows:

Availability (readiness of the equipment):

Downtime - equipment breakdown (the most common cause of equipment failures), stops for unscheduled tooling changes and unscheduled maintenance, failure of auxiliary equipment, stops not provided for in the production chart or schedule;

Changeover / adjustment - dismantling / installation of equipment, planned change of equipment, running of preparatory work, restrictions for consumables;

\section{Performance:}

Short-term equipment shutdown - can occur due to minor malfunctions, interruptions in delivery of materials. However these stops, which can last from a few seconds to 5 minutes, result in loss of productivity and reduced rate of productivity;

Decrease in processing speed - caused by equipment wear, decrease in power, increase in loading time, irregular operation of equipment, human error factor;

\section{Quality:}

Rejection and rework of defect product - producing of substandard products during the production process that do not meet the requirements of consumers. When reworking substandard products and eliminating defects, losses occur due to the waste of resources and the time spent on these production works;

Equipment start-up losses - rejects produced during startup, warm-up or other initial stages of equipment operation.

In various companies other types of losses may be added to the above classification of losses arising from the certain operations.

An important element in determining the efficiency of equipment operation is the arrangement and monitoring of the production process in order to collect information on losses that cause the greatest problems in the process of technological equipment operation. To process the obtained data, it is recommended to use Pareto analysis, which allows identifying a few but important factors that have the greatest impact on losses [10,11, 13, 25]. Ongoing monitoring of the overall efficiency of the equipment will reveal not only downtime due to breakdowns, but also losses due to inef-

\begin{tabular}{|c|c|c|c|c|c|}
\hline & \multicolumn{5}{|c|}{ TOTAL TIME OF OPERATION - 24•365 } \\
\hline $\mathbf{A}$ & \multicolumn{4}{|c|}{ NET OPERATION TIME } & $\begin{array}{l}\text { Off-work } \\
\text { hours }\end{array}$ \\
\hline B & \multicolumn{3}{|c|}{ PRODUCTIVE TIME } & Downtime & \\
\hline 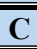 & \multicolumn{3}{|c|}{ PLANNED PRODUCTIVITY } & & \\
\hline$\overline{\mathbf{D}}$ & \multicolumn{2}{|c|}{ CURRENT PRODUCTIVITY } & $\begin{array}{c}\text { Reduction of } \\
\text { velocity }\end{array}$ & & \\
\hline $\mathbf{E}$ & \multicolumn{2}{|c|}{ CURRENT PRODUCTIVITY } & & & \\
\hline $\bar{F}$ & QQUALITY PRODUCT & Defect product & & & \\
\hline
\end{tabular}

Figure 4. Elements of $\mathrm{OEE}$ and losses related to the peculiar features of the equipment operation 
fective equipment setup, reduced productivity or time losses while waiting for materials to be delivered.

In order to identify losses associated with the operation of the equipment, the operation of vacuum filler for stuffing sausages, installed at one of the small company of the city, was studied and analyzed.
Based on the results of the studies and processing of data on types of losses that arose during the operation of a vacuum stuffer for sausages stuffing, the following parameters included in ratio were obtained (10). An example of calculating the coefficient of overall equipment effectiveness (OEE) for a vacuum filler is shown in Figures 5, 6, 7 [26].

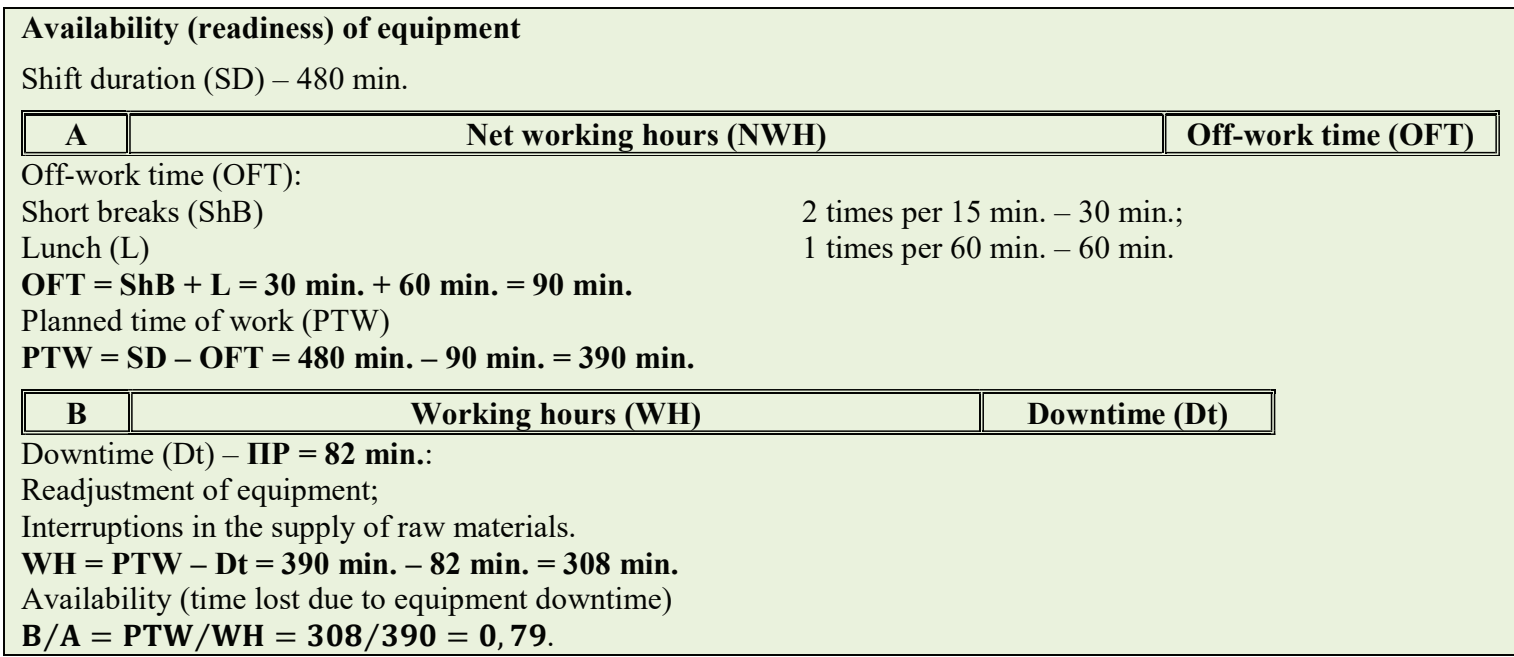

Figure 5. Calculation of readiness (availability) of equipment

\section{Productivity of equipment}

\begin{tabular}{|c||c|c|c|}
\hline \hline C & Planned productivity (PP) \\
\hline
\end{tabular}

Due to the limited volume of production, the planned productivity is: $\mathbf{P P}=\mathbf{8 0 0} \mathbf{~} \mathbf{~ g}$.

\begin{tabular}{|c|c|c|}
\hline D & Current productivity (CP) & $\begin{array}{c}\text { Loss of speed } \\
\text { (LS) }\end{array}$ \\
\hline
\end{tabular}

The loss in speed during the operation of the equipment led to a decrease in productivity by $192 \mathrm{~kg}$., i.e. $\mathbf{S D}=\mathbf{1 9 2} \mathbf{~ k g}$.

Loss of speed:

Idle operation with short-term stops of the equipment;

Running of the equipment at a decreased speed.

Current productivity $(\mathrm{CP})$ is equal to

$C P=P P-S D=800 \mathrm{~kg} .-192 \mathrm{~kg} .=608 \mathrm{~kg}$.

Performance (loss in speed due to short-term downtime of equipment and, as a result, a decrease in throughput capacity)

$\mathrm{D} / \mathrm{C}=\mathrm{CP} / \mathrm{PP}=608 / 800=0,76$.

Figure 6. Calculation of productivity rate of the equipment

\begin{tabular}{|c|c|c|c|}
\hline \multicolumn{3}{|c|}{ Quality of product } & \\
\hline $\mathbf{E}$ & \multicolumn{2}{|c|}{ Current productivity (CP) } & \\
\hline \multicolumn{4}{|c|}{ As it was defined by the performance rate of the equipment, current productivity равна $\mathbf{C P}=\mathbf{6 0 8} \mathbf{~ k g}$. } \\
\hline 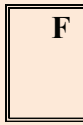 & Q Quality product (QP) & $\begin{array}{l}\text { Losses due to } \\
\text { defect product } \\
\text { (LDP) } \\
\end{array}$ & \\
\hline \multicolumn{4}{|c|}{$\begin{array}{l}\text { The losses from defect products caused by the disruption of the production process and the reduction in the } \\
\text { production volume amounted to LDP }=30 \mathrm{~kg} \text {. } \\
\text { Below is the calculation for the quality product rate } \\
\mathbf{Q P}=\mathbf{C P}-\mathbf{L D P}=\mathbf{6 0 8} \mathbf{~ k g} . \mathbf{- 3 0} \mathbf{~ k g} . \mathbf{5 7 8} \mathbf{~} \mathbf{~ g} \text {. }\end{array}$} \\
\hline \multicolumn{4}{|c|}{$\begin{array}{l}\text { Quality (quality losses due to the production of substandard products) } \\
\mathbf{F} / \mathbf{E}=\mathbf{Q P} / \mathbf{C P}=\mathbf{5 7 8} / \mathbf{6 0 8}=\mathbf{0}, \mathbf{9 5}\end{array}$} \\
\hline \multicolumn{4}{|c|}{ Overall equipment effectiveness (OEE) } \\
\hline \multicolumn{4}{|c|}{$\begin{array}{l}\text { Taking into account the data obtained on the availability, productivity rate of equipment and rate of quality product, } \\
\text { the overall equipment effectiveness }(\mathrm{OEE}) \text {, expressed as a percentage, is equal to } \\
\mathbf{O E E}=(\mathbf{B} / \mathbf{A}) \cdot(\mathbf{D} / \mathbf{C}) \cdot(\mathbf{F} / \mathbf{E}) \cdot \mathbf{1 0 0}=\mathbf{0}, \mathbf{7 9} \cdot \mathbf{0}, \mathbf{7 6} \cdot \mathbf{0}, \mathbf{9 5} \cdot \mathbf{1 0 0}=\mathbf{5 7} \% \text {. }\end{array}$} \\
\hline
\end{tabular}

Figure 7. Calculation of product quality, overall equipment effectiveness 
The overall equipment effectiveness is shown in Figure 8 below.

As it is obvious from the above data, the low efficiency of equipment during its operation was largely caused by a decrease in both the availability (readiness) of the equipment to work, and the parameter related to the productivity of the equipment. This fact indicates the necessity to find ways to reduce and control the downtime of equipment in order to eliminate losses during the operation of technological equipment, i. e. a key reserve for OEE growth is the elimination of losses. Similar studies can be run for each piece of equipment included in the production line for any producing task.

\section{Conclusion}

The inevitable requirements for increase in volume and range of semi-finished products, the most rational use of resources, and constant increase of nutritional value of food products determine the need for optimization and intensification of technological processes, as well as assess the quality of semi-finished products. The mechanization and automation of production of semi-finished food products is impossible without deeper understanding of the properties and parameters of raw materials used for their production, and the influence of various technological factors. In this regard, the demand for modern equipment for production of semi-finished food products with high productivity and reliability in operation is increasing.

In view of some reference target value based on the best data for availability, productivity and quality of the analyzed equipment, it is possible to get information on how to improve equipment operation by reducing downtime of this equipment.

Using the OEE concept and collecting the statistical data on causes of equipment failures, we are able to classify the factors that reduce the efficiency of equipment. In addition, information on factors influencing the loss of time during the operation of equipment will allow creating a system of equipment maintenance and repair (MRO), which can be used for planning of preventive maintenance and timely provision of spare parts and materials. For any fairly large and modern production it is crucially important.

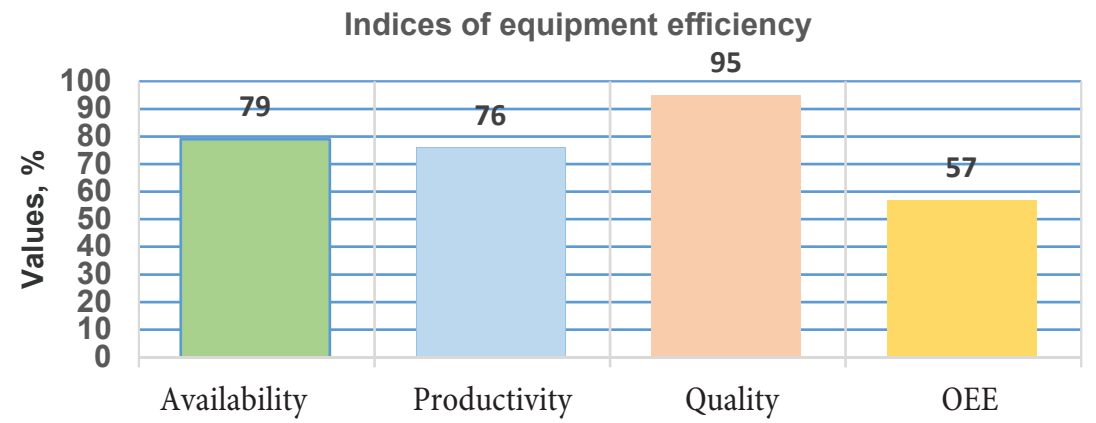

Figure 8. Indices of the overall efficiency of the equipment

\section{REFERENCES}

1. Allard Droste, A. (2007). Lean thinking, banish waste and create wealth in your corporation. Action Learning: Research and Practice 4(1), 105-106. https://doi.org/10.1080/14767330701233988 2. Kuzlyakina, Yu.A., Nikitina, M.A. (2019). Development concept of lean production in Russia and abroad. Vsyo o myase, 6, 22-26. https://doi.org/10.21323/2071-2499-2019-6-22-26 (In Russian)

3. Nikitina, M.A. (2019). Lean technologies in Russian and foreign enterprises. Meat Industry, 6. 8-10. (In Russian)

4. Ihueze, C.C., U-Dominic, C.M. (2017). Maximizing overall equipment effectiveness in a food processing industry: a case study. Archives of Current Research International, 11(4), 1-10. https://doi.org/10.9734/acri/2017/38187

5. Choubey, A. (2012). Study the initiation steps of Total Productive Maintenance in an organization and its effect in improvement of overall equipment effectiveness. International Journal of Engineering Research and Application, 2(4), 1709-1713.

6. Afefy, I. H. (2014). Implementation of total productive maintenance and overall equipment effectiveness evaluation. International Journal of Mechanical \& Mechatronics Engineering, 13(1), 60-75.

7. Sharma, A. K., Bhardwaj, A. (2012). Manufacturing performance and evolution of TPM. International Journal of Engineering Science and Technology, 4(3), 854-866.

8. Aleš, Z., Pavlů, J., Legát, V., Mošna, F., Jurča, V. (2019). Methodology of overall equipment effectiveness calculation in the context of industry 4.0 environment. Eksploatacja i Niezawodnosc, 21(3), 411-418. https://doi.org/10.17531/ein.2019.3.7

9. Tsarouhas, P. (2007). Implementation of total productive maintenance in food industry: a case study. Journal of Qual- ity in Maintenance Engineering, 13(1), 5-18. https://doi. org/10.1108/13552510710735087

10. Talib, F., Rahman, Z., Qureshi, M.N. (2010). Pareto analysis of total quality management factors critical to success for service industries. International Journal for Quality Research, 4(2), 155-168. 11. Powell, T., Sammut-Bonnici, T. (2015). Pareto analysis. Chapter in a book: Wiley Encyclopedia of Management. Publisher: John Wiley \& Sons. Project: Wiley Encyclopedia of Management. Vol 12 Strategic Management. 2015. - ISBN: 978-1-119-97251-8 12. Kume, H. (1985). Statistical methods for quality improvement. Tokyo: Association for Overseas Technical Scholarship 13. Netes, V.A. (2000, April 9-12). Pareto analysis approach to reliability improvement. 2d International Workshop on the Design of Reliable Communication Networks (DRCN2000). Munchen. 187-191. 14. Peleev, A.I. (1971). Technological equipment of meat industry enterprises. Moscow: Food industry. 1971. - 519 p. (In Russian) 15. Smirnov, M. B., Abdilova, G. B., Manapova, D.T. (2019). Equipment for forming food masses: An analytical review. Semey: "Pro100print". 2019. - 81 p. (In Russian)

16. Kudryashov, L.S. (2018). Defects and the ways of their elimination in cooked sausage production. Meat Industry, 30-33. (In Russian)

17. Lisitsyn, A.B., Nikitina, M.A., Zakharov, A.N., Sus, E.B., Nasonova, V.V., Lebedeva, L.I. (2016). Prediction of meat product quality by the mathematical programming methods. Theory and practice of meat processing, 1(1), 75-90. https://doi. org/10.21323/2414-438X-2016-1-1-75-90 (In Russian) 18. Kosoy, V.D. (1983). Improving the production process of cooked sausages. Moscow: Light and food industry. 1983. 272 p. (In Russian) 
19. Gorbatov, A.V. (1984). Rheology of meat and dairy products. Moscow: Light and food industry. 1979. - 384 p. (In Russian)

20. Gorbatov, A.V., Maslov, A. M. Machikhin, Yu.A. (1982). Structural and mechanical properties of food products. Moscow: Light and food industry. 1982. - 296 p. (In Russian)

21. Smirnov, M. B., Manapova, D.T., Abdilova, G. B. (2019). Graphoanalytical method of determining the viscosity of sausage forcemeats. Bulletin of the Shakarim State University of Semey, 4(88), 86-90.

22. Machikhin, Yu.A. (1990). Rheometry of food raw materials and products: A reference book. Moscow: Agropromizdat. 1990. - 271 p. (In Russian)
23. Schramm, G. (1994). A practical approach to rheology and rheometry. Karlsruhe: Gebrueder Haake GmbH. 1994. - 291 p.

24. Gorbatov, V.M., Gorbatov, A.V., Smirnov, M.B. (1983). Diagrams of velocities and deformations during non-isothermal flow of minced meat through tubes. Proceedings of the XXIX European Congress of Meat Industry Scientists. Italy, Room. 301-312. 25. Productivity Press Development Team. (1999). OEE for Operators: Overall Equipment Effectiveness. Taylor \& Francis, 1999. 63 p. ISBN9781563272219

26. Smirnov, M., Abdilova, G., (2020). Evaluation of the effectiveness of technological equipment. Vsyo o myase, 5S, 337-339. https://doi. org/10.21323/2071-2499-2020-5S-337-339 (in Russian)

\section{AUTHOR INFORMATION}

Mikhail B. Smirnov — candidate of technical sciences, associate professor, professor of the Department “Technological Equipment and Mechanical Engineering”, NAO “Shakarim University of Semey”, 071412, Republic of Kazakhstan, Semey, Glinka str. 20A.

Tel.: +7 777-633-88-08, E-mail: mbs_semgu@mail.ru

ORCID: htpps://orcid.org/0000-0001-9610-5066

Galiya B. Abdilova - candidate of technical sciences, acting associate professor of the Department "Technological Equipment and Mechanical Engineering», "Shakarim University of Semey”, 071412, Republic of Kazakhstan, Semey, Glinka str. 20A.

Tel.: +7 708-537-24-32, E-mail: abdilova1979@bk.ru

ORCID: htpps://orcid.org/0000-0002-6647-6314

* corresponding author

All authors are responsible for the work and data presented.

All authors made an equal contribution to the work.

The authors were equally involved in writing the manuscript and are equally responsible for plagiarism.

The authors declare no conflict of interest.

Received 03.02.2021 Accepted in revised 12.03.2021 Accepted for publication 25.03.2021 